УДК 378

\title{
АНАЛИЗ ПРОБЛЕМ ИСПОЛЬЗОВАНИЯ ИНФОРМАЦИОННЫХ ТЕХНОЛОГИЙ ПРИ ОБУЧЕНИИ АНГЛИЙСКОМУ ЯЗЫКУ СТУДЕНТОВ-ЮРИСТОВ
}

Зайцева Серафима Евгеньевна к.П.н., доцент ФГКОУ ВО «Московский университет МВД России имени В.Я. Кикотя»

\begin{abstract}
Аннотация: Применение компьютеров на занятиях по английскому языку значительно повышает интенсивность учебного процесса. Существенным недостатком использования компьютера в учебном процессе при реализации важнейшей психолого-педагогической функции обучения предъявлении и принятии учащимися целей и задач учебно-познавательной деятельности - является острый дефицит непосредственного общения преподавателя и обучающегося.

Ключевые слова: информационные технологии, компьютерные обучающие программы, эффективность обучения, информационно-учебная деятельность.
\end{abstract}

\section{ANALYSIS OF THE PROBLEMS OF USING INFORMATION TECHNOLOGIES IN TEACHING ENGLISH TO LAW STUDENTS}

\section{Zaitseva Serafima Evgenyevna}

\begin{abstract}
The use of computers in English classes significantly increases the intensity of the educational process. A significant disadvantage of using a computer in the educational process in the implementation of the most important psychological and pedagogical function of training - the presentation and acceptance by students of the goals and objectives of educational and cognitive activity - is an acute shortage of direct communication between the teacher and the student.

Key words: information technologies, computer training programs, learning efficiency, information and educational activities.
\end{abstract}

Информатизация общества - это глобальный социальный процесс, особенность которого состоит в том, что доминирующим видом деятельности в 
сфере общественного производства является сбор, накопление, продуцирование, обработка, хранение, передача и использование информации, осуществляемые на основе современных средств микропроцессорной и вычислительной техники, а также на базе разнообразных средств информационного обмена.

Одним из приоритетных направлений процесса информатизации современного общества является информатизация образования - внедрение средств новых информационных технологий в систему образования. Это сделает возможным совершенствование механизмов управления системой образования на основе использования автоматизированных банков данных научно - педагогической информации, информационно-методических материалов, а также коммуникационных сетей; совершенствование методологии и стратегии отбора содержания, методов и организационных форм обучения, соответствующих задачам развития личности обучаемого в современных условиях информатизации общества; создание методических систем обучения, ориентированных на развитие интеллектуального потенциала обучаемого, на формирование умений самостоятельно приобретать знания, осуществлять информационно-учебную,

экспериментально

исследовательскую деятельность, разнообразные виды самостоятельной деятельности по обработке информации; создание и использование компьютерных тестирующих, диагностирующих, контролирующих и оценивающих систем [1, с. 35].

В настоящее время значительные преобразования в области образования затронули и обучение иностранному языку в юридическом вузе. В частности стали интенсивно внедрятся в учебный процесс новые информационные технологии, такие как использование Интернет-ресурсов, обучающих компьютерных программ и т.п.

Компьютерные программы в обучении английскому языку стали использоваться с 80-х годов прошлого века. Общеизвестно, что автоматизированные обучающие системы (АОC) относятся к так называемым комбинированным техническим средствам обучения. Они предназначены для реализации с помощью компьютера, работающего в диалоговом режиме, функций по предъявлению учебной информации в удобной для восприятия форме, для индивидуализированного управления учебной деятельностью в ходе программированного, проблемного обучения, контроля знаний, а также для обеспечения доступа к вычислительным, информационно-справочным и другим ресурсам компьютера. 
Система образования, по мнению многих исследователей, не может быть независимой от общественного и политического устройства государства, она во все времена откликалась на социальный заказ. Политика государства в последнее время направлена на то, чтобы внедрить информационные технологии в вузы, превратить стихийный процесс в управляемый и контролируемый, привлечь к работе над новыми учебными материалами специалистов в предметных областях, стимулировать компьютерные фирмы к созданию электронной обучающей продукции для российских студентов. И сейчас, под напором далеко не самых приятных обстоятельств - пандемии, это происходит.

Необходимо, чтобы каждый преподаватель понял простую мысль: компьютер в учебном процессе - не механический педагог, не заместитель или аналог преподавателя, а средство при обучении студентов, усиливающее и расширяющее возможности его обучающей деятельности. То, что преподаватель желает получить в результате использования машины, в неё необходимо запрограммировать. Таким образом, компьютер берёт на себя львиную долю рутинной работы преподавателя, высвобождая ему время для творческой деятельности, которая на современном уровне развития техники не может быть отдана компьютеру.

Как известно, пригодность технических средств обучения и контроля для использования на занятиях по иностранному языку определяется по следующим критериям. Во-первых, они должны способствовать повышению производительности труда и эффективности учебного процесса. Во-вторых, обеспечивать немедленное и постоянное подкрепление правильности учебных действий каждого обучающегося. В-третьих, повышать сознательность и интерес к изучению языка. В-четвёртых, обеспечивать оперативную обратную связь и пооперационный контроль действий всех обучаемых. В-пятых, обладать возможностью быстрого ввода ответов без длительного их кодирования и шифрования [2, с. 12].

Как показывает практика, из всех существующих средств обучения компьютер наилучшим образом «вписываются» в структуру учебного процесса, наиболее полно удовлетворяет дидактическим требованиям и максимально приближает процесс обучения английскому языку к реальным условиям. Компьютеры могут воспринимать новую информацию, определённым образом обрабатывать её и принимать решения, могут запоминать необходимые данные, воспроизводить движущиеся изображения, контролировать работу таких технических средств обучения, как синтезаторы речи, видеомагнитофоны, 
магнитофоны. Компьютеры существенно расширяют возможности преподавателей по индивидуализации обучения и активизации познавательной деятельности учащихся в обучении английскому языку. Каждый обучающийся получает возможность работать в своём ритме. Например, при работе с заданиями по развитию логического мышления и навыков речи каждый студент - будущий юрист может использовать свои мыслительные ресурсы и знания в соответствии со своими индивидуальными возможностями (рис.1).

\section{Study the situation: Lucy tells Andrew about being on a jury.}

Your task is to complete each part of the sentences 1) to 7) with one of the word combinations a) to g). Use each word combination once only. Andrew: Hi. How are you? I haven't seen you 1) ... .

Lucy: Hi. I'm fine. I've been busy.

Andrew: What have you been doing?

Lucy: I was called 2) ... .

Andrew: Wow. What was it like?

Lucy: It was good. It did not take 3) ... and was fun.

Andrew: What happened? I have never been on a jury.

Lucy: I got a letter telling me to go to the court house, and I was then taken 4) ... .

Andrew: What was the case about?

Lucy: It was about a teenager who had done a lot of robberies.

Andrew: Did you find him 5) ...?

Lucy: Yes. It was easy. There was so much evidence that there was no doubt he 6) ... .

Andrew: Why did it take so long then?

Lucy: There was just so much evidence. The evidence took 7) ... and then we only needed fifteen minutes to reach our decision.

Andrew: Ok, good.
a) ... to a court room.
b) ... to do jury duty.
c) ... to be guilty?
d) ... for a few days.
e) ...three days to present
f) ... did the crime.
g) ... too long

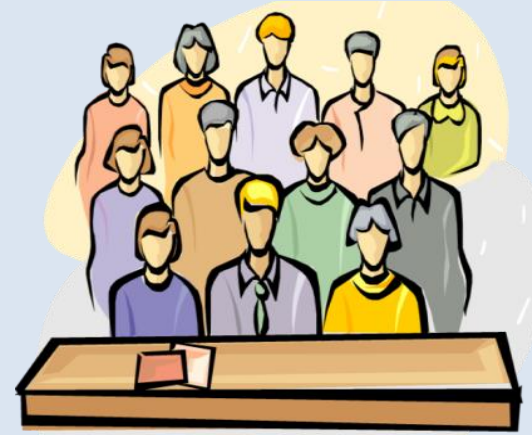

\section{Рис. 1. Пример задания по развитию навыков речи}

Применение компьютеров на занятиях по английскому языку в юридическом вузе значительно повышает интенсивность учебного процесса. При компьютерном обучении усваивается гораздо большее количество материала, чем это делалось за одно и то же время в условиях традиционного обучения. Кроме того, материал при использовании компьютера усваивается прочнее. 
Компьютер обеспечивает и всесторонний (текущий, рубежный, итоговый) контроль учебного процесса. Контроль, как известно, является неотъемлемой частью учебного процесса и выполняет функцию обратной связи между обучающимся и преподавателем. При использовании компьютера для контроля качества знаний учащихся достигается и большая объективность оценки. Кроме того, компьютерный контроль позволяет значительно сэкономить учебное время.

Благоприятные возможности создают компьютеры и для организации самостоятельной работы студентов-юристов на занятиях по английскому языку. Обучающиеся могут использовать компьютер как для изучения отдельных тем, так и для самоконтроля полученных знаний (рис.2).

Study English idioms \& idiomatic expressions. Make your own sentences using idioms \& idiomatic expressions from above.

\begin{tabular}{l|l}
$\begin{array}{l}\text { To throw } \\
\text { the book at } \\
\text { somebody }\end{array}$ & to punish someone very severely \\
\hline $\begin{array}{l}\text { A short } \\
\text { sharp shock }\end{array}$ & a quick, severe punishment \\
\hline $\begin{array}{l}\text { Do time } \\
\text { Face the } \\
\text { music }\end{array}$ & $\begin{array}{l}\text { to receive punishment; to take responsibility } \\
\text { for something bad }\end{array}$ \\
\hline $\begin{array}{l}\text { To grease } \\
\text { someone's } \\
\text { palm }\end{array}$ & to bribe someone \\
\hline
\end{tabular}

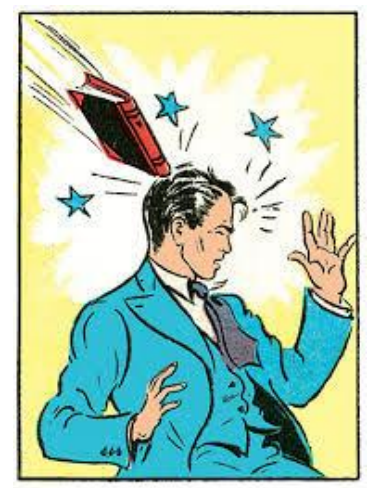

To throw the book at somebody

\section{Рис. 2. Пример задания по контролю активной лексики}

Однако, сказав о достоинствах компьютеров, следует отметить и некоторые недостатки. Диалектичность педагогических явлений состоит в том, что какое бы то ни было положительное само по себе свойство или качество целостного учебно-воспитательного процесса оно оборачивается своей противоположностью и становится крайне нежелательным при неумеренном, гипертрофированном проявлении, подавляющем другие, не менее важные свойства. Это замечание имеет самое непосредственное отношение к 
индивидуализации обучения, тем более что в условиях компьютеризации существенно меняются условия взаимодействия педагога и учащихся.

Уже на первом этапе обучения английскому языку, в процессе постановки целей и задач предстоящей познавательной деятельности учащихся преподаватель участвует опосредованно. Непосредственное предъявление заданий обучающемуся осуществляет компьютер. Конечно, преподаватель должен принимать самое активное участие в составлении обучающих программ, определяющих последовательность действий учащегося в решении той или иной задачи. Но в реализации важнейшей психолого-педагогической функции обучения - предъявлении и принятии учащимися целей и задач учебно-познавательной деятельности - в условиях компьютеризации возможен острый дефицит непосредственного общения, живого слова преподавателя.

Хотя передача всех функций преподавателя машине в принципе возможна, идею полной автоматизации обучения, как справедливо подчеркнул на всероссийской конференции, посвященной психологическим проблемам создания и использования компьютера Б.Ф. Ломов, едва ли можно рассматривать как практически реализуемую и гуманную. Обучение немыслимо без воспитывающего воздействия личности обучающего на учащихся, а для этого необходим их непосредственный контакт.

В заключении необходимо подчеркнуть, что внедрение в учебный процесс использования мультимедийных обучающих программ по английскому языку для студентов-юристов вовсе не исключает традиционные методы обучения, а гармонично сочетается с ними на всех этапах обучения: ознакомление, тренировка, применение, контроль. Но использование компьютера позволяет не только многократно повысить эффективность обучения, но и стимулировать учащихся к дальнейшему самостоятельному изучению английского языка.

\section{Список литературы}

1. Носенко Э. Л. Применение информационных технологий в образовании. - СПб.: Златоуст, 2018.

2. Полат Е.С. Интернет на уроках иностранного языка. // Иностранные языки в школе, № 2, 2014.

(C) С.Е. Зайцева, 2021 